\title{
Food insecurity and its association with changes in nutritional habits among adults during the COVID-19 confinement measures in Belgium
}

\author{
Stefanie Vandevijvere*, Karin De Ridder, Sabine Drieskens, Rana Charafeddine, \\ Finaba Berete and Stefaan Demarest \\ Sciensano, Service of Lifestyle and Chronic Diseases, Sciensano, J. Wytsmanstraat 14, 1050 Brussels, Belgium
}

Submitted 10 September 2020: Final revision received 23 November 2020: Accepted 2 December 2020: First published online 9 December 2020

\begin{abstract}
Objective: To assess food insecurity and its association with changes in nutritional habits among Belgian adults during confinement due to COVID-19.

Design: Three cross-sectional online health surveys were conducted during March-May 2020. Multinomial logistic regression models were used to determine associations between self-reported changes in fruit, vegetable, soft drink and sweet and salted snack consumption or weight as dependent variables and food insecurity indicators as independent variables, adjusted for gender, household composition, educational attainment and household income.

Setting: Belgium.

Participants: In total, 8640 adults recruited by convenience sampling.

Results: About 10.4\% of Belgians often or sometimes feared food shortages, $5.0 \%$ were often or sometimes short of food without money to buy more and $10 \cdot 3 \%$ often or sometimes could not afford to eat a healthy diet during confinement. These percentages were highest among single-parent families (26.7, 14.4 and $23.4 \%$, respectively). Adults who often or sometimes feared that food would run out during confinement had significantly higher odds of decreased $v$. unchanged fruits $(3.53 ; 95 \% \quad \mathrm{CI}=2.06,6.05)$ and vegetables $(5.42$; $95 \% \mathrm{CI}=2 \cdot 90,10 \cdot 11)$ consumption and significantly higher odds of increased $v$. unchanged soft drink consumption (3.79; $95 \% \mathrm{CI}=2 \cdot 20,6 \cdot 54)$. Similar results were found for adults who often or sometimes ran out of food and for adults who often or sometimes were not able to afford a healthy diet.

Conclusion: Food insecurity during the COVID-19 confinement measures in Belgium was associated with adverse changes in most dietary behaviours. A strong government response is needed to tackle malnutrition and food insecurity to protect public health from ongoing and future pandemics.
\end{abstract}

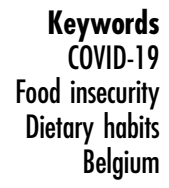

Keywords

ood insecurity

Belgium
Bels habits
COVID-19 was declared a pandemic by the WHO in March 2020 and has since evolved into an unprecedented public health crisis leading to economic and social crises. In several countries, the COVID-19 pandemic has disrupted access to food, led to food shortages, loss of disposable household income, increased food prices and altered dietary practices ${ }^{(1)}$. The pandemic has threatened millions of families living with or at risk for development of food insecurity ${ }^{(2)}$. In a world where nutrition-related issues, including obesity, malnutrition and food insecurity, already impact the majority of its population ${ }^{(3)}$, further exacerbation of food insecurity, malnutrition and obesity imposed by the COVID-19 pandemic are expected and likely to magnify disparities in healthy lifestyle behaviours, aggravating the global burden of diet-related chronic diseases ${ }^{(4)}$. In addition, malnutrition has been associated with a higher risk for SARS-COV-2 infection and, when contracted, more severe cases (e.g. hospitalisation, mechanical

*Corresponding author: Email stefanie.vandevijvere@sciensano.be

(C) The Author(s), 2020. Published by Cambridge University Press on behalf of The Nutrition Society 
ventilation) $)^{(5)}$. In particular, malnutrition is suggested to contribute to obesity just as obesity may contribute to malnutrition, and both are driven by unhealthy dietary behaviours, especially in the presence of food insecurity ${ }^{(6)}$.

Food insecurity is generally defined as consistent worry or concern about access to adequate amounts of affordable and nutritious foods at all times ${ }^{(7)}$. Conceptualisations of food insecurity in high-income countries primarily focus on the economic aspect; for example, the Household Food Security Survey Module ${ }^{(8)}$, which is commonly used in the USA and Canada, measures uncertain or inadequate access to food due to financial constraints. The lack of consistent access to nutritious foods has been found associated with chronic physical and mental health problems ${ }^{(9)}$.

In Belgium, strict confinement measures to curb the spread of COVID-19 were introduced on 13 March 2020. The confinement measures included closure of hotels, bars and restaurants as well as schools/universities, nonessential industries and cultural, recreational or sportive activities.

The aim of the current study was to assess different levels of food insecurity in Belgium and associations with changes in nutritional habits among the adult population during the COVID-19 confinement measures.

\section{Methods}

Three online health surveys were organised during the confinement period. The first COVID-19 health survey was launched 3 weeks after the start of the confinement (2 April), the second survey took place 2 weeks later (16 April) and the third one was distributed on 28 May 2020. All three surveys were developed with LimeSurvey version 3 and were available online for 1 week.

\section{Sampling and recruitment}

No sampling was performed. Recruitment of adults residing in Belgium was done through launching the surveys on the website of Sciensano and other health-related organisations (health insurance, community centers, etc.), through snow balling and by the press and social media.

People who had indicated in a given survey that they would like to take part in the next one received an invitation through the e-mail address they provided.

\section{Study population}

The data for the purposes of this study were derived from the second and the third COVID-19 health survey, as the second survey included specific questions on changes in nutrition-related behaviours while the third survey included questions on household food insecurity. In total, 53419 Belgian adults participated in the second survey, while 37409 participated in the third survey. In total, 15849 participants mentioned in survey 3 that they participated in the previous surveys, agreed to link their data and provided an email address for the linkage. For 8640 participants, the data from survey 2 and survey 3 could effectively be linked based on e-mail, gender, year of birth and post code.

\section{Variables}

\section{Food Insecurity}

The questions on food insecurity at the household level were derived from the USDA Household Food Security Survey Module ${ }^{(8)}$ and enquired about the last $30 \mathrm{~d}$. For the following three questions, it was asked whether they were often true, sometimes true or never true for the household (option do not know/refused was also foreseen):

- I/We worried whether my/our food would run out before I/we got money to buy more

- The food that I/we bought did not last, and I/we did not have money to get more

- I/we could not afford to eat healthy balanced meals

Three indicators were created:

- Often or sometimes feared that food would run out before there is money to buy more over the last month (yes/no).

- Often or sometimes the food purchased did not last long enough, and there was no money to buy more over the last month (yes/no)

- Often or sometimes not being able to afford to eat a healthy and balanced diet over the last month (yes/no)

\section{Changes in dietary behaviours}

For four selected food groups (the same ones as included in the regular Health Interview Surveys), the question 'Has the consumption of the following foods increased, remained unchanged or decreased since the start of the confinement (13 March 2020)?' was included:

1. Fruits, excluding juice squeezed from fresh fruit or made from concentrate

2. Vegetables or salad, excluding potatoes and fresh juice or juice made from concentrate

3. Sugared soft drinks, i.e. lemonade, cola or ice tea (not include 'light')

4. Sweet or salty snacks such as candy, chocolate, cake, biscuits, ice cream, chips, etc.

\section{Changes in weight status}

A question on change in weight status since the start of the confinement (13 March 2020) was included with the following answer options: (1) Yes, lost weight (2) Yes, gained weight (3) No, my body weight remained stable (4) Don't know/refused. 


\section{Socio-demographic characteristics}

Gender, educational attainment (secondary school diploma or less $v$. higher education), household composition (living alone, couple without child(ren), couple with child(ren), living alone with child(ren), living with parents, family, friends and other) and average monthly household's net income (after deducting taxes and social security contributions) (less than 1500 euro per month, 1500-2000 euro per month, 2000-2500 euro per month, 2500-5000 euro per month and more than 5000 euro per month) were defined as socio-demographic covariates which could have a possible association with food insecurity.

\section{Data analysis}

The indicators for food insecurity were described by household composition and education level. Since the study sample was biased at the level of region (underrepresentation of the Flemish Region and overrepresentation of the Walloon Region), gender (overrepresentation of women), age group (underrepresentation of the youngest (18-24) and oldest (65+)) and educational attainment (underrepresentation of the low educated), poststratification weights were calculated using Labor Force Survey (LFS) 2016 data as auxiliary database. The calculation of the weights was based on cross classified LFS 2016 data on age, gender, province and education.

As ordered logistic regression was not possible due to proportional odds assumptions not being met, multinomial logistic regression models were used to determine the associations between self-reported changes in dietary behaviours or weight status as the dependent variables and food insecurity indicators as the independent variables, adjusted for gender, household composition, educational attainment and average monthly disposable household income. Both crude and adjusted OR with $95 \% \mathrm{CI}$ and the P-value were presented. All the analyses were performed with SAS ${ }^{\circledR} 9.4$.

\section{Results}

\section{Food insecurity in Belgium}

About $10.4 \%$ of Belgian adults (10.8 \% of women and $8.9 \%$ of men) often or sometimes feared food shortages over the last month (May 2020). This percentage was lowest among over-65s (5.0\%) and highest among the age group 2544 years $(13.4 \%)$. There were large differences between individuals according to the household composition: the fear of food shortage was highest among single parent families with children (26.7\%) and single persons (14.7\%) and lowest among couples without children (6.2\%). There was a significant difference between individuals with a diploma of secondary education or lower (13.0\%) and individuals with a diploma of higher education (3.8\%) (Fig. 1).

About $5.0 \%$ of Belgian adults $(5.2 \%$ of women and $4.8 \%$ of men) were often or sometimes short of food and had no money to buy more over the last month (May 2020). This percentage was lowest among over-65s ( $2 \cdot 1 \%)$ and highest among the $25-34$ and $35-44$ age groups ( 6.1 and $6.7 \%$, respectively). Also for this indicator there

\section{HOUSEHOLD COMPOSITION}

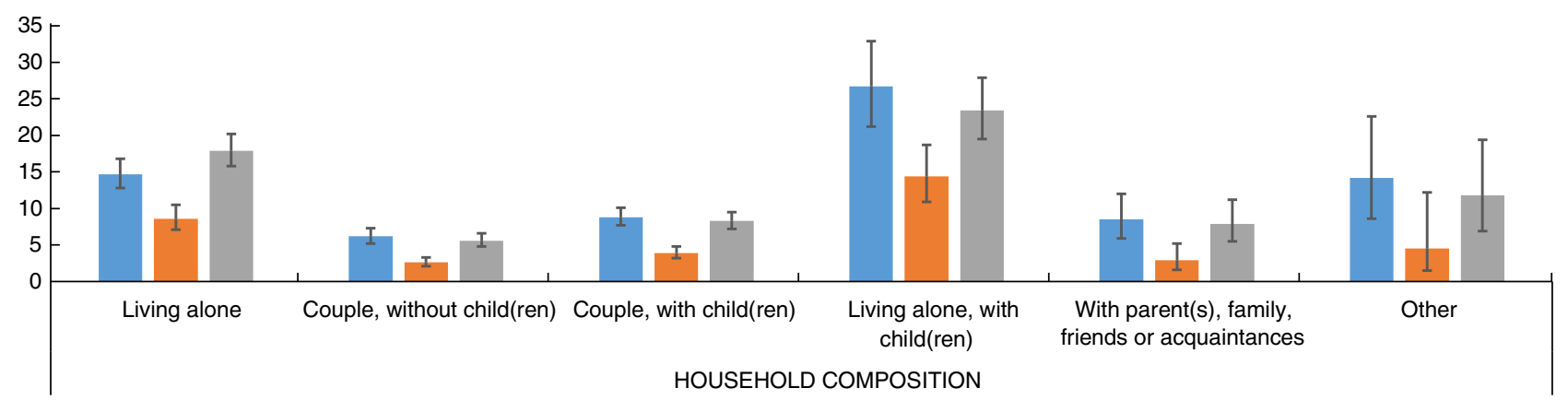

EDUCATION LEVEL

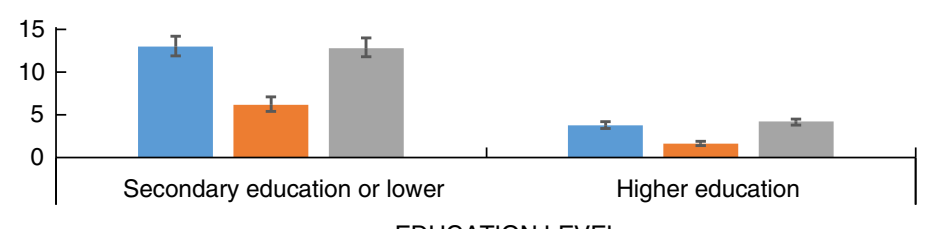

EDUCATION LEVEL

Fig. 1 (colour online) Percentage $(95 \% \mathrm{Cl})$ of the population aged 18 years and over who often or sometimes feared food shortages ( $n 30$ 114), who effectively suffered from food shortages ( $n 30$ 065) and who could not afford to eat a healthy and balanced diet ( $n 30$ 093) during the confinement measures according to the household composition (above) and education level (below); third

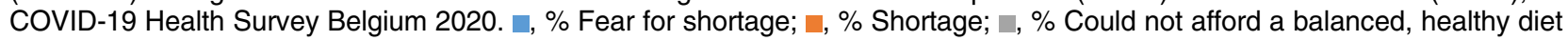


Table 1 Study population characteristics ( $n$ 8122); second and third COVID-19 health survey, Belgium 2020

\begin{tabular}{|c|c|c|c|}
\hline Characteristic & & $n$ & Weighted \% \\
\hline \multirow[t]{3}{*}{ Region } & Flanders & 4998 & $59 \cdot 0$ \\
\hline & Brussels & 887 & $9 \cdot 8$ \\
\hline & Wallonia & 2222 & $31 \cdot 3$ \\
\hline \multirow[t]{6}{*}{ Household composition } & Living alone & 1577 & $20 \cdot 6$ \\
\hline & As a couple, without child(ren) & 2818 & 33.4 \\
\hline & As a couple, with child(ren) & 2675 & $25 \cdot 0$ \\
\hline & Living alone with children & 486 & $4 \cdot 0$ \\
\hline & With my parent(s), family, friends or acquaintances & 475 & $16 \cdot 0$ \\
\hline & Other & 88 & 0.97 \\
\hline \multirow[t]{2}{*}{ Gender } & Male & 2631 & $48 \cdot 1$ \\
\hline & Female & 5484 & 51.9 \\
\hline \multirow[t]{2}{*}{ Educational attainment } & Secondary diploma or less & 1886 & $65 \cdot 3$ \\
\hline & Higher education & 6095 & $34 \cdot 7$ \\
\hline \multirow{6}{*}{$\begin{array}{l}\text { Make ends meet with household } \\
\text { income during the lockdown }\end{array}$} & With great difficulty & 195 & 3.4 \\
\hline & With difficulty & 335 & $5 \cdot 4$ \\
\hline & With some difficulty & 1006 & $15 \cdot 9$ \\
\hline & Fairly easily & 2195 & $31 \cdot 3$ \\
\hline & Easily & 2388 & $27 \cdot 8$ \\
\hline & Very easily & 1815 & $16 \cdot 2$ \\
\hline \multirow[t]{5}{*}{ Average household income } & Less than 1500 euro per month & 504 & $10 \cdot 6$ \\
\hline & Between 1500 and 2000 euro per month & 949 & $16 \cdot 2$ \\
\hline & Between 2000 and 2500 euro per month & 1335 & $15 \cdot 4$ \\
\hline & Between 2500 and 5000 euro per month & 3837 & $40 \cdot 2$ \\
\hline & More than 5000 euro per month & 1066 & $9 \cdot 0$ \\
\hline \multirow[t]{3}{*}{ Food insecurity } & $\begin{array}{l}\text { Often or sometimes feared that the food runs out } \\
\text { before there is money to buy more. }\end{array}$ & 492 & $9 \cdot 7$ \\
\hline & $\begin{array}{l}\text { Often or sometimes the food purchased did not last } \\
\text { long enough and there was no money to buy more. }\end{array}$ & 219 & $5 \cdot 0$ \\
\hline & $\begin{array}{l}\text { Often or sometimes was not able to afford to eat a } \\
\text { healthy and balanced diet }\end{array}$ & 495 & $9 \cdot 8$ \\
\hline \multirow[t]{8}{*}{ Change in consumption } & Fruits - decreased & 623 & $9 \cdot 0$ \\
\hline & Fruits - increased & 1102 & $15 \cdot 2$ \\
\hline & Vegetables - decreased & 316 & $5 \cdot 2$ \\
\hline & Vegetables - increased & 933 & 11.9 \\
\hline & Soft drinks - decreased & 503 & $7 \cdot 7$ \\
\hline & Soft drinks - increased & 567 & $8 \cdot 8$ \\
\hline & Sweet and salty snacks - increased & 2720 & 33.4 \\
\hline & Sweet and salty snacks - decreased & 527 & $8 \cdot 3$ \\
\hline \multirow[t]{4}{*}{ Weight change } & Unchanged & 4179 & 51.4 \\
\hline & Lost weight & 1040 & $14 \cdot 1$ \\
\hline & Gained weight & 2011 & 23.4 \\
\hline & Missing & 873 & $11 \cdot 1$ \\
\hline
\end{tabular}

were large differences between individuals according to the household composition: the percentage of individuals experiencing food shortages was highest among single parent families with children (14.4\%) and single persons (8.6\%) and lowest among couples without children (2.6\%) (Fig. 1). There was a significant difference between individuals with a diploma of secondary education or lower $(6.2 \%)$ and individuals with a diploma of higher education (1.6\%) (Fig. 1).

About $10.3 \%$ of Belgian adults (10.0 \% of women and $9.6 \%$ of men) could often or sometimes not afford to eat a healthy and balanced diet over the last month (May 2020). This percentage was lowest among the over- $65 \mathrm{~s}$ (5.2\%) and highest among the 25-34 age group (13.6\%). The percentage of individuals who could not afford to eat healthy and balanced food was highest among single parent families with children $(23.4 \%)$ and single persons $(17.9 \%)$ and lowest among couples without children
(5.6\%). There was a significant difference between individuals with a diploma of secondary education or lower $(12.8 \%)$ and individuals with a diploma of higher education (4.2\%) (Fig. 1).

\section{Associations between changes in nutritional babits during confinement and different indicators of food insecurity in Belgium}

The regression analyses included $23 \cdot 1 \%$ of participants from survey wave 3 , for which a link could be made to the results on nutritional behaviour changes included in survey wave 2 . About $52 \%$ of those participants were female, $21 \%$ was living alone and $4 \%$ living alone with children. About $35 \%$ of those participants attained higher education. About $25 \%$ of these participants had some or great difficulty to make ends meet (Table 1).

Adults who often or sometimes feared over the last month that food would run out before there is money to 
Table 2 Associations between changed consumption of certain food groups (decreased and increased $v$. unchanged) or weight status (decreased and increased $v$. unchanged) during the confinement measures and food insecurity measured by three different indicators by means of crude and adjusted ${ }^{\star} \mathrm{OR}$ with $95 \% \mathrm{Cl}$ and p-value; second and third COVID-19 health survey, Belgium 2020

\begin{tabular}{|c|c|c|c|c|c|c|c|c|c|c|c|c|c|}
\hline & \multirow[b]{3}{*}{ Change } & \multicolumn{6}{|c|}{ Crude OR } & \multicolumn{6}{|c|}{ Adjusted OR $\dagger$} \\
\hline & & \multicolumn{2}{|c|}{$\begin{array}{l}\text { Fear food running } \\
\text { outł }\end{array}$} & \multicolumn{2}{|c|}{ Food running out§ } & \multicolumn{2}{|c|}{$\begin{array}{l}\text { Healthy diet unaf- } \\
\text { fordableף }\end{array}$} & \multicolumn{2}{|c|}{$\begin{array}{l}\text { Fear food running } \\
\text { out }\end{array}$} & \multicolumn{2}{|c|}{ Food running out§ } & \multicolumn{2}{|c|}{$\begin{array}{l}\text { Healthy diet unaf- } \\
\text { fordableף }\end{array}$} \\
\hline & & OR & $95 \% \mathrm{Cl}$ & OR & $95 \% \mathrm{Cl}$ & OR & $95 \% \mathrm{Cl}$ & OR & $95 \% \mathrm{Cl}$ & OR & $95 \% \mathrm{Cl}$ & OR & $95 \% \mathrm{Cl}$ \\
\hline \multirow[t]{2}{*}{ Fruit } & Increased $v$. unchanged & 1.37 & $0.78,2.34$ & 0.44 & $0.24,0.80^{*}$ & 1.38 & $0.73,2.61$ & 1.30 & $0.73,2 \cdot 31^{*}$ & 0.38 & $0.19,0.75^{\star}$ & 1.24 & $0.65,2.34$ \\
\hline & Decreased $v$. unchanged & $4 \cdot 16$ & $2 \cdot 06,8 \cdot 39^{*}$ & 4.82 & $1 \cdot 81,12 \cdot 87^{*}$ & 4.99 & $2 \cdot 57,9 \cdot 66^{\star}$ & 3.53 & $2 \cdot 06,6 \cdot 05^{\star}$ & 3.59 & $1 \cdot 69,7 \cdot 61^{*}$ & 4.05 & $2 \cdot 39,6 \cdot 86^{*}$ \\
\hline \multirow{2}{*}{ Vegetables } & Increased $v$. unchanged & 2.04 & $1 \cdot 20,3 \cdot 46^{*}$ & 1.32 & $0.71,2.47$ & 2.03 & $1.18,3.49^{\star}$ & 1.92 & $1.09,3 \cdot 38^{*}$ & $1 \cdot 12$ & $0.57,2.21$ & 1.78 & $0.99,3.19$ \\
\hline & Decreased $v$. unchanged & $6 \cdot 86$ & $2 \cdot 92,16 \cdot 14$ & 10.44 & $3.63,30.04^{\star}$ & $9 \cdot 35$ & $4 \cdot 34,20 \cdot 13^{\star}$ & 5.42 & $2 \cdot 90,10 \cdot 11^{*}$ & 7.58 & $3.45,16 \cdot 66^{\star}$ & $6 \cdot 74$ & $3 \cdot 68,12 \cdot 35^{\star}$ \\
\hline \multirow[t]{2}{*}{ Soft drinks } & Increased $v$. unchanged & 5.04 & $2 \cdot 50,10 \cdot 19^{\star}$ & $5 \cdot 72$ & $2 \cdot 15,15 \cdot 25^{\star}$ & 4.04 & $1.92,8.48^{*}$ & 3.79 & $2 \cdot 20,6 \cdot 54^{*}$ & 3.97 & $1 \cdot 79,8 \cdot 79^{\star}$ & $2 \cdot 96$ & $1 \cdot 69,5 \cdot 19^{*}$ \\
\hline & Decreased $v$. unchanged & 1.40 & $0.76,2.58$ & $1 \cdot 14$ & $0.49,2.66$ & 1.31 & $0.76,2.26$ & 1.43 & $0.70,2.95$ & 1.23 & $0.49,3.06$ & $1 \cdot 26$ & $0.66,2.40$ \\
\hline \multirow[t]{2}{*}{ Sweet and salty snacks } & Increased $v$. unchanged & $2 \cdot 30$ & $1.48,3.57^{*}$ & 2.51 & $1 \cdot 26,4.98^{*}$ & 2.09 & $1 \cdot 32,3 \cdot 32^{*}$ & 1.87 & $1 \cdot 24,2 \cdot 81^{*}$ & 2.09 & $1.11,3.93^{*}$ & 1.76 & $1 \cdot 11,2 \cdot 81^{*}$ \\
\hline & Decreased $v$. unchanged & $2 \cdot 88$ & $1 \cdot 54,5 \cdot 38^{*}$ & $2 \cdot 24$ & $1 \cdot 05,4 \cdot 79^{*}$ & 2.90 & $1 \cdot 46,5 \cdot 78^{\star}$ & 2.35 & $1 \cdot 13,4 \cdot 89^{*}$ & 1.82 & $0.77,4.31$ & $2 \cdot 12$ & $0.97,4.61$ \\
\hline \multirow{2}{*}{ Weight status } & Increased $v$. unchanged & 2.93 & $1.44,5.98^{*}$ & 3.83 & $1.33,10.99^{\star}$ & $3 \cdot 17$ & $1.52,6 \cdot 61^{*}$ & 2.24 & $1 \cdot 29,3 \cdot 89^{\star}$ & $2 \cdot 81$ & $1 \cdot 25,6 \cdot 33^{*}$ & $2 \cdot 45$ & $1 \cdot 38,4 \cdot 34^{*}$ \\
\hline & Decreased $v$. unchanged & 1.98 & $1 \cdot 39,2 \cdot 83^{*}$ & $2 \cdot 35$ & $1 \cdot 38,4 \cdot 03^{\star}$ & 2.91 & $2.07,4.09^{*}$ & 1.57 & $1.07,2.32$ & 1.84 & $1 \cdot 03,3 \cdot 31^{*}$ & $2 \cdot 51$ & $1.71,3 \cdot 67^{\star}$ \\
\hline
\end{tabular}

${ }^{\star} P<0.01$.

†Adjusted for gender, household composition, education level, region, average disposable household income.

FFear food running out: Often or sometimes fear that the food runs out before there is money to buy more over the last month.

sFood running out: Otten or sometimes the food purchased did not last long enough and there was no money to buy more over the last month.

IHealthy diet unaffordable: Often or sometimes not being able to afford to eat healthy and balanced food over the last month. 
buy more during confinement had significantly higher odds of decreased $v$. unchanged fruit $(3.53 ; 95 \% \mathrm{CI}=2 \cdot 06,6 \cdot 05)$ and vegetable $(5 \cdot 42 ; 95 \% \mathrm{CI}=2 \cdot 90,10 \cdot 11)$ consumption and significantly higher odds of increased $v$. unchanged soft drink consumption (3.79; 95\% CI $=2.20$, 6.54), adjusted for socio-demographic covariates. Similar results were found for adults who often or sometimes ran out of food over the last month before acquiring sufficient financial means to buy more (fruit: $3 \cdot 59 ; 95 \% \mathrm{CI}=1 \cdot 69,7 \cdot 61$; vegetables: $7 \cdot 58$; $95 \% \mathrm{CI}=3.45$, 16.66; soft drinks: 3.97; $95 \% \mathrm{CI}=1.79,8.79)$ and for adults who often or sometimes were not able to afford a healthy and balanced diet over the last month (fruit: $4.05 ; 95 \% \mathrm{CI}=2.39,6.86$; vegetables: 6.74; $95 \% \quad \mathrm{CI}=3.68, \quad 12.35$; soft drinks: 2.96 ; $95 \%$ $\mathrm{CI}=1.69,5 \cdot 19)$. For sweet and salty snack consumption and weight change the results were mixed. Adults who were food insecure according to all three indicators had significantly higher odds of both decreased $v$. unchanged and increased $v$. unchanged sweet and salty snack consumption. The same was found for weight change (Table 2).

\section{Discussion}

This population-weighted online survey conducted during the COVID-19 confinement measures in Belgium found that food insecurity was considerably high, in particular for adults living alone, with or without children. However, it is important to note that we do not have baseline data to compare these figures to levels of food insecurity in Belgium before the start of the COVID-19 pandemic. The study showed that the risk for adverse changes in most dietary behaviours was significantly higher among those experiencing food insecurity, from not being able to afford a healthy diet, to actually running out of financial means to buy sufficient food. Changes in food prices and disposable household income may also have impacted dietary behaviours during confinement.

Strengths of the survey include the large sample, limitations include convenience sampling, the use of multinomial logistic regression, self-reported intake and weight status, different assessment timing for food insecurity and nutritional habits, lack of data on ethnicity, limited information on dietary habits and the lack of baseline measures on food insecurity for Belgium as part of national surveys.

Food insecurity has been scarcely assessed in Belgium. It is not part of the regular health interview surveys or the food consumption surveys. The best estimate currently available is Eurostat's food poverty indicator: In 2018, $8.8 \%$ of people 16 years or older in Belgium declared that they were unable to afford a meal with meat, chicken, fish (or vegetarian equivalent) every second day ${ }^{(10)}$. In 2019, 168476 people (about $1.5 \%$ of the population) used at least once the services of the Belgian Federation of Food
Banks. This number has been growing steadily since $2005^{(11)}$.

The United Nations World Food Program has estimated that, due to COVID-19, 265 million people could face acute food insecurity by the end of 2020, almost doubling the number of people under severe threat of food insecurity around the world ${ }^{(12)}$. A study in Vermont among a convenience sample of 3219 respondents found that there was nearly a one-third increase $(32.3 \%)$ in household food insecurity since COVID-19 ( $P<0.001)$, with $35.5 \%$ of food insecure households classified as newly food insecure ${ }^{(13)}$. Respondents experiencing household food insecurity had higher odds of facing food access challenges and utilising coping strategies, including two-thirds of households eating less since COVID-19 $(P<0.001)$. The rise in food insecurity prevalence in the USA has induced a $98 \%$ increase in the demand and reliance on receiving food from local food banks and an increase in enrollment and service expansion of supplemental nutrition aid programmes ${ }^{(14)}$.

Due to rising levels of food insecurity in several countries, altered dietary habits, such as shown in this study, and the link between malnutrition and severity of SARSCOV-2 infection, the COVID-19 pandemic has presented numerous clear opportunities to shift unhealthy eating behaviours and unhealthy food environments to those that promote healthier dietary behaviours. A stronger response from governments is urgently needed to tackle the multiple burdens of malnutrition and food insecurity to protect public health from ongoing and future pandemics. Monitoring of food insecurity should be included in planned and ongoing population health surveys.

The continuity of food assistance programmes combined with tailored efforts to ensure access to diverse and nutritious diets to vulnerable population groups are paramount to alleviate food insecurity and the cascading effects leading to negative health outcomes.

In conclusion, food insecurity during the COVID-19 confinement measures in Belgium was associated with adverse changes in most dietary behaviours. A strong government response is needed to tackle malnutrition and food insecurity to protect public health from ongoing and future pandemics.

\section{Acknowledgements}

Acknowledgements: The authors would like to thank all the individuals who participated in the COVID health surveys in Belgium. Financial support: No funding was obtained for this study. Conflicts of interest: The authors declare they have no conflicts of interest in regard to this study. Authorship: K.D. and S.D. lead the surveys; S.D., R.C., F.B. and S.V. contributed to the development of the 
surveys; R.C., F.B. and S.V. conducted the analyses; S.V. wrote the paper; all authors critically revised draft versions of the manuscript and approved the final version. Ethics of buman subject participation: The survey was approved by the Human Ethics Committee of Ghent University Hospital.

\section{References}

1. Torero M (2020) Without food, there can be no exit from the pandemic. Nature 580, 588-589.

2. Paslakis G, Dimitropoulos G \& Katzman DK (2020) A call to action to address COVID-19-induced global food insecurity to prevent hunger, malnutrition, and eating pathology. Nutr Rev Published online: 11 July 2020. doi: 10.1093/ nutrit/nuaa069.

3. 2020 Global Nutrition Report [Internet] (2020) Country Nutrition Profiles. https://globalnutritionreport.org/ (accessed December 2020).

4. Huizar MI, Arena R \& Laddu DR (2020) The global food syndemic: The impact of food insecurity, Malnutrition and obesity on the healthspan amid the COVID-19 pandemic. Prog Cardiovasc Dis Published online: 10 July 2020. doi: 10.1016/j.pcad.2020.07.002.

5. Gao F, Zheng KI, Wang X-B et al. (2020) Obesity Is a Risk Factor for Greater COVID-19 Severity. Diabetes Care 43, e72-e74.

6. Swinburn BA, Kraak VI, Allender S et al. (2019) The global syndemic of obesity, undernutrition, and climate change: the lancet commission report. Lancet 393, 791-846.
7. Coleman-Jensen A, Rabbitt MP, Gregory CA et al. (2018) Housebold Food Insecurity in the United States in 2017 [Internet]. Washington, DC: USDA Economic Research Service

8. USDA Economic Research Service (2012) US Household Food Security Survey Module: Six-Item Short Form [Internet]. https://www.ers.usda.gov/media/8282/short2012 .pdf (accesed September 2012).

9. Martin MS, Maddocks E, Chen Y et al. (2016) Food insecurity and mental illness: disproportionate impacts in the context of perceived stress and social isolation. Public Health 132, 86-91.

10. Eurostat (2020) Inability to afford a meal with meat, chicken, fish (or vegetarian equivalent) every second day by level of activity limitation, sex and age Eurostat. https://appsso. eurostat.ec.europa.eu/nui/show.do?dataset=hlth_dm030\& lang=en (accessed December 2020).

11. Belgische Federatie van Voedselbanken(2020) Belgische Federatie van Voedselbanken [Belgian Federation of Foodbanks]. https://www.foodbanks.be/nl (accessed December 2020).

12. Food Security Information Network (2020) Global Report on Food Crises | World Food Programme. wfp.org (accessed December 2020).

13. Niles MT, Bertmann F, Belarmino EH et al. (2020) The early food insecurity impacts of COVID-19. Nutrients Published online: 13 May 2020. doi: 10.3390/nu12072096.

14. Feeding America (2020) Feeding America Network Faces Soaring Demand, Plummeting Supply Due to COVID-19 Crisis. https://www.feedingamerica.org/about-us/pressroom/soaring-demand-plummeting-supply (accessed April 2020). 